\title{
Avaliação de fatores de risco de cães sororreagentes à leptospira spp. e sua distribuição espacial, em área territorial urbana
}

Welligton Borges da SILVA ${ }^{1}$ Ligia Barroso SIMÕES 2 Ana Lúcia Scarelli LOPES ${ }^{1}$ Carlos Roberto PADOVANI ${ }^{3}$ Hélio LANGONI ${ }^{4}$ José Rafael MODOLO ${ }^{4}$

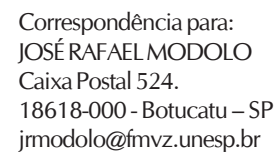

Recebido para publicação: 15/06/2005 Aprovado para publicação: 13/06/2006

\author{
1 - Departamento de Saúde Animal, Saúde Pública Veterinária e Segurança \\ Alimentar da Faculdade de Medicina Veterinária e Zootecnia da \\ Universidade Estadual Paulista, Botucatu - SP \\ 2 - Departamento de Microbiologia e Imunologia do Instituto de Biociências \\ da Universidade Estadual Paulista, Botucatu - SP \\ 3 - Departamento de Bioestatística do Instituto de Biociências da \\ Universidade Estadual Paulista, Botucatu - SP \\ 4 - Departamento de Higiene Veterinária e Saúde Pública da Universidade \\ Estadual Paulista, Botucatu - SP
}

\section{Resumo}

Objetivou-se avaliar os fatores de risco de cães sororreagentes à aglutinina antileptospírica e sua distribuição espacial, em uma área territorial urbana. Foram colhidas 1.000 amostras de sangue de cães, em 20 postos, distribuídos, homogeneamente, pela área territorial urbana de $32 \mathrm{~km}^{2}$ da cidade de Botucatu, Estado de São Paulo, Brasil. O diagnóstico foi realizado pela prova de soroaglutinação microscópica, com 24 sorovares de Leptospira spp. A análise estatística foi feita por meio do teste de Goodman, considerando-se o nível de 5\% de significância. Para verificar-se a ocorrência de conglomerados, foi aplicado o teste de varredura espacial, processado por meio do programa SaTScan. Demonstrou-se que 17,9\% dos soros reagiram à Leptospira spp. ( $\mathrm{p}<0,0001)$. Quanto ao manejo de criação, os cães que tinham acesso à rua $(22,14 \%)$ apresentaram-se $(\mathrm{p}<0,05)$ como os mais reagentes, em relação aos que não o tinham $(14,83 \%)$. Os resultados da estatística de varredura apontaram apenas um conglomerado significativo, influenciado pela composição etária da população em risco. Incorporando-se cada uma das co-variáveis de sexo, raça e acesso à rua, à co-variável idade, verificou-se que o fator acesso à rua foi o que mais contribuiu para explicar o conglomerado encontrado. $\mathrm{O}$ acesso à rua e a idade mostraram ser os fatores de risco mais importantes no excesso de animais sororreagentes, no conglomerado encontrado, sendo o sorovar castellonis o que apresentou a maior taxa nas amostras sorológicas caninas da área territorial urbana. A identificação de um conglomerado com cães sororreagentes acima do esperado permite que sejam tomadas medidas preventivas localizadas.

\section{Introdução}

A leptospirose é uma importante zoonose contemporânea que acomete humanos, animais silvestres e domésticos, em todo o mundo ${ }^{1,2}$. Atualmente, é considerada uma infecção reemergente ${ }^{3,4}$. É mais difundida em climas tropicais do que em regiões temperadas 5 .

A água tem papel primordial na difusão e manutenção das leptospiras na natureza e assume uma particular importância na transmissão da doença, que ocorre por meio do contato com a água contaminada de rios, lagoas e canais ou oriunda de chuvas fortes e inundações ${ }^{6}$. Animais que vivem em
Palavras-chave: Leptospirose. Cães. Fatores de risco. 
áreas urbanas periféricas, cujas condições sanitárias e de infra-estrutura são precárias (junto a lixões, esgoto a céu aberto, depósitos de materiais descartados e restos alimentares, além de promiscuidade com outras espécies animais) constituem-se, particularmente, em populações de risco ${ }^{7}$.

No Brasil e na maior parte do mundo, a $L$. interrogans sorovar canicola e a L. interrogans sorovar icterohaemorrhagiae têm sido, tradicionalmente, associadas com leptospirose canina ${ }^{8}$. Essa enfermidade vem assumindo grande importância, tanto nos países em desenvolvimento quanto nos desenvolvidos ${ }^{9,10}$. Dentre os animais domésticos, em área urbana, os cães podem ser considerados os principais transmissores da doença aos seres humanos, uma vez que podem eliminar leptospiras vivas, por vários meses, sem apresentar sinais clínicos ${ }^{3,5,11}$. Nesse sentido, foi observado ${ }^{12}$ que, no período de 1962 a 1978, de 820 casos humanos de leptospirose, notificados no Centro de Controle de Doenças dos Estados Unidos da América (CDC), 58\% foram de infecção por cães.

Prévia infecção ou vacinação estão associadas a títulos menores de 300; podem ser encontrados, porém, títulos próximos a 800 de sovares canicola e icterohaemorrhagiae, que, geralmente, não persistem após três meses ${ }^{1}$. Também alguns cães desenvolvem elevados títulos (aproximadamente 3.200), após vacinação com esses sorovares. Depois de um tempo, ocorre o declínio do título, que pode persistir por até seis meses após a vacinação $^{3}$. As vacinas contra leptospirose, aplicadas rotineiramente nos cães domésticos, são capazes de protegê-los contra a doença, mas não contra o estado de portador renal ${ }^{13}$.

Considerando-se a importância da leptospirose canina na saúde animal, o impacto da doença no homem, o risco de infecção representado pelo contato íntimo entre o homem e o cão e a interação do cão com o meio ambiente, propôs-se verificar a importância dos cães no contexto epidemiológico e seu papel como sentinelas. Nesse sentido, o estudo da distribuição espacial dos resultados sorológicos permitiu mapear as áreas de maior risco de se adquirir leptospirose, além de apontar a ocorrência de possíveis conglomerados espaciais. Um conglomerado ou agrupamento espacial (cluster) é um grupo de ocorrências geograficamente limitado, de tamanho e concentração tais, que é improvável acontecerem por mero acaso ${ }^{14}$.

Dessa forma, o presente trabalho teve por objetivos a obtenção da freqüência de resultados sorológicos para leptospirose, em cães da área territorial urbana do município de Botucatu, Estado de São Paulo (SP), Brasil, e a avaliação da sua distribuição espacial e de alguns fatores de risco, como idade, sexo, raça e manejo de criação da população canina, verificando-se a ocorrência ou não de conglomerados espaciais de cães sororreagentes à Leptospira spp., entre os postos de colheita.

\section{Materiais e métodos}

\section{Caracterização do município de Botucatu - SP}

O município de Botucatu localiza-se na região centro-sul do Estado de São Paulo (22 52 de latitude sul e 4826 de longitude oeste), situando-se cerca de 805 metros acima do nível do mar. Possui $1.483 \mathrm{~km}^{2}$, sendo $32 \mathrm{~km}^{2}$ pertencentes à área territorial urbana. Sua população é estimada em 113.771 habitantes. O clima é subtropical úmido, com invernos secos e verões quentes, com temperatura média de $19^{\circ} \mathrm{C}$ e precipitação pluviométrica de $1.250 \mathrm{~mm}$. A vegetação consiste em mata pluvial e cerrado $^{15}$.

\section{Caracterização da amostragem \\ Alocação dos animais e dos postos}

Durante a 33a Campanha Anual de Vacinação Anti-Rábica, em 2001, coordenada pela disciplina de Planejamento de Saúde Animal e Veterinária Preventiva da Faculdade de Medicina Veterinária e Zootecnia - UNESP - de Botucatu - SP , foram colhidas 1.000 amostras de sangue de cães, de acordo com o procedimento 
estabelecido no estudo. As amostras, aproximadamente $6 \%$ do total de 16.838 cães vacinados durante a campanha, foram colhidas em 20 postos de vacinação, representativos do total de 40 postos, distribuídos, homogeneamente, em cinco regiões da área territorial urbana do Município. A área de abrangência de cada posto era, em média, de $0,8 \mathrm{~km}^{2}$. Para o procedimento de alocação do animal ( $2^{\circ}$ estágio), levou-se em conta o plano de amostragem sistemática, sob a definição de que, a partir do animal selecionado, os dois seguintes seriam descartados. Quanto aos postos de coleta de dados e sangüínea, procedeu-se, em primeiro estágio, ao sorteio (amostragem casual) geográfico dos 20 postos de vacinação. $\mathrm{O}$ tamanho amostral, 1.000 cães, foi determinado considerandose uma taxa de $10 \%$ de erro de estimação, com nível de $95 \%$ de confiança ${ }^{16}$.

\section{Colheita de sangue}

Foram colhidos, aproximadamente, $10 \mathrm{~mL}$ de sangue por animal, em tubo de vidro estéril (vacutainer) de $15 \mathrm{~mL}$, pela punção da veia cefálica ou da jugular, e encaminhados, em seguida, ao laboratório da disciplina de Zoonoses da FMVZ Unesp Campus de Botucatu, SP. No laboratório, foram dessorados e centrifugados a 3.000 rotações por minuto $(\mathrm{rpm})$, durante 10 minutos. O soro foi acondicionado em microtubos de plástico (eppendorf) de 1,5 $\mathrm{mL}$ e mantido em freezer a $-20^{\circ} \mathrm{C}$, até o momento da realização da técnica de soroaglutinação microscópica (SAM).

\section{Inquérito para os proprietários dos cães}

Foi aplicado um inquérito aos proprietários (informantes) dos cães, no qual constavam a identificação do animal, idade, sexo, raça e também o manejo de criação.

Técnica de soroaglutinação microscópica (SAM)

A prova de soroaglutinação microscópica foi realizada segundo as normas do Ministério da Saúde ${ }^{13}$, utilizando- se 24 sorovares de Leptospira spp., a saber: Australis, Bratislava, Autumnalis, Butembo, Castellonis, Bataviae, Brasiliensis, Canicola, Whitcombi, Cynopteri, Djasiman, Sentot, Grippotyphosa, Hebdomadis, Copenhageni, Icterohaemorrhagiae, Javanica, Panama, Pomona, Pyrogenes, Hardjo, Wolffi, Shermani e Tarassovi. Como reagentes, consideraram-se títulos iguais ou superiores a 100.

\section{Análise estatística}

As informações coletadas foram armazenadas na planilha EXCEL, na qual as distribuições freqüenciais foram calculadas. Considerou-se o teste de Goodman ${ }^{17,18}$ para a discussão da associação entre duas variáveis respostas, envolvendo contrastes entre e dentro de populações multinomiais. Os resultados foram discutidos fixando-se o nível de 5\% de significância ${ }^{19}$.

\section{Geoprocessamento e análise por conglomerados}

Para verificar-se a ocorrência de conglomerados, foi aplicado o teste de varredura, processado por meio do programa SaTScan ${ }^{20}$. A hipótese nula foi a de que o risco era o mesmo em todos os postos de colheita. A distribuição dos resultados sorológicos foi considerada do tipo Poisson, isto é, proporcional ao tamanho da população da área. O método consiste em rastrearem-se todos os pontos, colocando-se o centro de uma janela circular em cada ponto e variando-se o raio, à procura do conglomerado mais provável. Esse método permite que o centro da janela circular se mova, de forma que, para uma dada posição e tamanho, a janela inclua um conjunto diferente de vizinhos próximos. Ao passar por todos os postos de vacinação, seu raio varia, continuamente, de zero ao raio máximo, que nunca inclui mais do que 50\% da população total. Cria-se, assim, um grande número de janelas circulares diferentes, cada uma contendo um conjunto de vizinhos. A função de probabilidade é maximizada sobre todas as janelas, identificando-se aquela que constitui o agrupamento mais provável. A 
distribuição da razão de probabilidade máxima sob a hipótese nula e seu valor de "p" simulado correspondente são obtidos pela repetição do mesmo exercício analítico, num grande número de réplicas aleatórias (999) do conjunto de dados gerados sob a hipótese nula, numa simulação do tipo Monte Carlo. A hipótese de nulidade foi considerada rejeitada quando $\mathrm{p}<0,05$.

Para avaliação da influência de fatores de risco, na formação de possíveis conglomerados, quatro co-variáveis foram introduzidas na análise, ajustando-se, separadamente, para a distribuição por idade, sexo, raça e manejo de criação dos cães. Para avaliação do efeito conjunto das co-variáveis, cada uma delas foi acrescida, passo a passo, na análise.

\section{Resultados}

Considerando-se como animais reagentes os que apresentaram titulações iguais ou superiores a 100 , os resultados obtidos demonstraram que 179/1.000 $(17,9 \%)$ soros de cães foram reagentes à Leptospira spp., e 821/1.000 (82,1\%) não o foram ( $p<0,0001)$. O intervalo de $95 \%$ de confiança para a leptospira, nos cães amostrados, estabeleceu os limites de ocorrência entre $15,52 \%$ e 20,28\%.

A variação percentual de $15,52 \%$ a $20,28 \%$ estabelece limites estatísticos para menos ou para mais, referentes ao índice de $17,9 \%$, e, se outros estudos forem realizados, na mesma população, espera-se que $95 \%$ deles também permaneçam com índices dentro desse intervalo $(17,9 \% \pm 2,38 \%)$.

As características da população canina estudada revelaram que os cães compreenderam as faixas etárias variando de 3 meses a 1 ano (22,3\%), de 1,1 ano a 5 anos $(52,9 \%)$ e a partir de 5,1 anos $(24,8 \%)$. Os machos representaram $54,9 \%$, e as fêmeas, 45,1\%; os cães sem raça definida, $67,1 \%$, enquanto que os com raça definida, $32,9 \%$.

Os cães que tiveram acesso à rua, 93/ $420(22,14 \%)$, apresentaram-se com títulos sorológicos maiores e com diferença significativa $(p<0,05)$, em relação aos que não tiveram esse acesso, 86/580 (14,83\%).

Em casos de coaglutinação, em que mais de uma variante sorológica apresentou titulação para uma mesma amostra de soro, considerou-se a positividade de um soro para o sorovar em que se observou maior titulação (Tabela 1).

Em algumas situações, os casos de coaglutinações apresentaram titulações máximas idênticas para dois ou mais sorovares. Dessa forma, as coaglutinações foram apresentadas separadamente, uma vez que não foi possível estabelecer o sorovar infectante mais provável (Tabela 2).

A maior porcentagem de soros reagentes encontra-se no Posto 1, sucessivamente, de forma decrescente, até o Posto 20 (Figura 1): (1) Vila São Luís - 19/ 43 (44,19\%); (2) Jardim São Vicente - 15/ 43 (34,88\%); (3) COHAB-I - 16/51 (31/ 37\%); (4) Jardim Continental - 15/48 (31,25\%); (5) Jardim Peabiru - 13/50 (26\%); (6) Vila Antártica - 13/66 (19/7\%); (7) Vila Assunção - 11/60 (18/33\%); (8) Vila Operária - 9/50 (18\%); (9) Vila dos Lavradores - 7/41 (17,07\%); (10) Parque Marajoara - 8/50 (16\%); (11) Jardim Monte Mor - 8/51 (15,69\%); (12) Centro - 5/36 (13,89\%); (13) Vila Santa Teresinha - 7/53 (13,21\%); (14) Vila Real - 7/55 (12,73\%); (15) Lageado - 5/50 (10\%); (16) Rubião Júnior - 5/51 (9,8\%); (17) Vila Sônia - 5/ 51 (9,8\%); (18) Vila Maria - 4/50 (8\%); (19) Parque 24 de Maio - 4/51 (7,84\%); (20) COHAB-V - 3/50 (6\%). Técnicas de geoprocessamento, como a interpolação por Inverso do Quadrado da Distância, permitiram a visualização da distribuição dos resultados sorológicos, em pontos não amostrados (Figura 1). Os níveis em cor cinza predizem o percentual de soros reagentes nesses pontos.

Não se considerando as co-variáveis, um único conglomerado foi detectado pelo teste de varredura espacial $(\mathrm{p}=0,001)$, compreendendo três postos de vacinação (Vila Antártica, Vila São Luís e Jardim 
Tabela 1 - Distribuição dos maiores títulos de anticorpos contra Leptospira spp. em cães, frentea 24 sorovares testados, Botucatu, São Paulo, Brasil, $2001^{\text {a }}$

\begin{tabular}{ccccccccc}
\hline & \multicolumn{7}{c}{ Títulos de anticorpos (UI) } & Total $(\%)$ \\
\cline { 2 - 7 } Sorovar & 100 & 200 & 400 & 800 & 1.600 & 3.200 & 6.400 & $39(28,68 \%)$ \\
castellonis & 8 & 8 & 12 & 9 & 2 & - & - & $26(19,12 \%)$ \\
autumnalis & 9 & 6 & 4 & 6 & 1 & - & - & $24(17,65 \%)$ \\
pyrogenes & 4 & 4 & 6 & 6 & 3 & 1 & - & $15(11,03 \%)$ \\
icterohaemorrhagiae & 9 & 1 & 4 & 1 & - & - & - & $13(9,56 \%)$ \\
canicola & 2 & 3 & 2 & 1 & - & 2 & 3 & $6(4,41 \%)$ \\
australis & 2 & 1 & 2 & 1 & - & - & - & $5(3,68)$ \\
shermani & - & - & - & - & - & 3 & 2 & $2(1,47 \%)$ \\
copenhageni & - & - & 2 & - & - & - & - & $2(1,47 \%)$ \\
grippotyphosa & 1 & - & - & - & - & 1 & - & $1(0,73 \%)$ \\
brasiliensis & 1 & - & - & - & - & - & - & $1(0,73 \%)$ \\
butembo & - & 1 & - & - & - & - & - & $1(0,73 \%)$ \\
panama & 1 & - & - & - & - & - & - & $1(0,73 \%)$ \\
wolffi & - & 1 & - & - & - & - & - & $136(100 \%)$ \\
Total & 37 & 25 & 32 & 24 & 6 & 7 & 5 & \\
\hline
\end{tabular}

a Casos de coaglutinações, em que mais de uma variante sorológica apresentou titulação para uma mesma amostra de soro. Considerou-se a positividade de um soro para o sorovar em que se observou maior titulação, mesmo assim, não constam nesta tabela os sorovares com ocorrência de empate na titulação máxima.

Continental). O número de cães sororreagentes encontrados nessa área foi de 47, sendo esperados, sob a hipótese nula da casualidade, 28,1 cães. Levando-se em consideração a idade como fator de risco, os postos da Vila Antártica e do Jardim Continental deixaram de fazer parte do agrupamento, que continuou significativo para a Vila São Luís (Tabela 3), com 19 cães sororreagentes, quando o esperado era de 8,43 .

Incorporando-se cada uma das covariáveis à co-variável idade, o agrupamento da Vila São Luís manteve-se significativo para idade e sexo e idade e raça $(p<0,05)$ e não significativo para idade e acesso à rua $(\mathrm{p}>0,05)$. Dessa forma, os resultados indicam que o conglomerado formado pela Vila São Luís, possivelmente, se explica pela composição demográfica (faixa etária) e pelo manejo da criação. Sendo que, as variáveis sexo e raça não interferiram para a formação de conglomerados na Vila São Luís.

\section{Discussão}

A taxa de cães sororreagentes à Leptospira spp., em área territorial urbana de
Botucatu, SP, foi de 17,9\% (179/1.000) $\mathrm{p}<0,0001$, com limites de $95 \%$ de confiança, variando de $15,52 \%$ a $20,28 \%$. Porcentagens próximas à encontrada foram verificadas em sorologias realizadas em cães, em 14 cidades do Estado de São Paulo, com 17,3\% (137/ $795)^{21}$. Foram observados, em Patos, nordeste do Brasil, taxas de 20,2\% (23/ $114)^{22}$, e, na Índia ${ }^{23}$, obtiveram-se $17,19 \%$ $(11 / 64)$ de cães sororreagentes, apesar de, entre os estudos citados e este experimento, ocorrerem variações na quantidade de sorovares, incluindo a utilização de alguns sorovares diferentes, nas provas laboratoriais. Taxa menor foi observada na África do Sul ${ }^{24}, \operatorname{com} 1,5 \%$ (6/400), fortemente explicada pelo clima quente e seco de Pretória, desfavorável à manutenção do agente no ambiente. Freqüências de aglutininas antileptospíricas maiores foram encontradas em Salvador, Estado da Bahia, Brasil $^{25}$, com taxa de 44,3\% (294/663), e na Cidade do México, México ${ }^{26}$, com 38,51\% (52/135), atribuídas a abundantes chuvas torrenciais, umidade, temperaturas elevadas e populações pobres, sem benefícios sanitários. Nesses trabalhos, o número de sorovares utilizados nas provas laboratoriais foi menor do que o do presente estudo, 
Tabela 2 - Distribuição dos maiores títulos de anticorpos contra Leptospira spp. com coaglutinações, em cães da área territorial urbana de Botucatu, São Paulo, Brasil, 2001"a

\begin{tabular}{|c|c|c|c|c|c|c|c|c|c|}
\hline \multirow{2}{*}{ Sorovar } & \multicolumn{8}{|c|}{ Títulos de anticorpos (UI) } & \multirow[b]{2}{*}{ Total $(\%)$} \\
\hline & 100 & 200 & 400 & 800 & 1.600 & 3.200 & 6.400 & 12.800 & \\
\hline castellonis/canicola & 3 & 5 & 5 & 1 & - & 1 & 2 & - & $17(39,54 \%)$ \\
\hline canicola/pyrogenes & 1 & 1 & 2 & 2 & - & - & - & - & $6(13,96 \%)$ \\
\hline castellonis/pyrogenes & - & - & - & 2 & 1 & - & - & - & $3(6,98 \%)$ \\
\hline castellonis/canicola/pyrogenes & 1 & - & - & - & 1 & - & - & - & $2(4,65 \%)$ \\
\hline castellonis/icterohaemorrhagiae & 1 & 1 & - & - & - & - & - & - & $2(4,65 \%)$ \\
\hline canicola/icterohaemorrhagiae & 1 & - & - & 1 & - & - & - & - & $2(4,65 \%)$ \\
\hline icterohaemorrhagiae /pyrogenes & 2 & - & - & - & - & - & - & - & $2(4,65 \%)$ \\
\hline australis/shermani & - & - & 1 & 1 & - & - & - & - & $2(4,65 \%)$ \\
\hline aust./cast./can./pyr./ictero./sher. & 1 & - & - & - & - & - & - & - & $1(2,33 \%)$ \\
\hline $\begin{array}{c}\text { australis/hebdomadis/ } \\
\text { copenhageni }\end{array}$ & - & 1 & - & - & - & - & - & - & $1(2,33 \%)$ \\
\hline autumnalis/ grippotyphosa & - & 1 & - & - & - & - & - & - & $1(2,33 \%)$ \\
\hline autumnalis/hebdomadis & 1 & - & - & - & - & - & - & - & $1(2,33 \%)$ \\
\hline autumnalis/ icterohaemorrhagiae & - & - & - & - & - & - & - & 1 & $1(2,33 \%)$ \\
\hline castellonis/canicola/copenhageni & - & - & 1 & - & - & - & - & - & $1(2,33 \%)$ \\
\hline castellonis/canicola/hardjo & - & - & - & 1 & - & - & - & - & $1(2,33 \%)$ \\
\hline Total & 11 & 9 & 9 & 8 & 2 & 1 & 2 & 1 & $43(100 \%)$ \\
\hline
\end{tabular}

1 Constam nesta tabela as coaglutinações com ocorrência de empate na titulação máxima.

destacando-se, ainda, as diferenças climáticas regionais.

O manejo de criação demonstrou ser um fator relevante, uma vez que o resultado da análise estatística revelou diferença significativa $(p<0,05)$ entre o índice de cães reagentes que tinham acesso à rua $-22,14 \%$ (93/420) - e os que não o tinham - 14,83\% (86/580). De acordo com um estudo realizado em Pelotas, sul do Brasil ${ }^{27}$, os cães que não permaneciam confinados tinham 2,61 vezes mais chances de adquirir a doença, provavelmente porque esses animais teriam entrado em contato com cães estranhos e com outros fatores de risco. Isso mostra que a domiciliação do cão é fundamental para diminuir o risco de contaminação. Contrariando essas afirmações, pesquisadores, ao realizarem um inquérito sorológico para leptospirose em cães, em Santana de Parnaíba, SP, Brasil ${ }^{28}$, não encontraram essa associação, porque, segundo os autores, a quantidade de cães reagentes amostrados não permitiu chegar a tal índice.

Dentro do contexto de manter-se uma linha de pesquisa somente com leptospiras patogênicas, as mais prováveis existentes na região, foram selecionadas 24 variantes sorológicas. $\mathrm{Na}$ tabela 1 , definemse a sua representação e distribuição, sendo o maior título considerado como o provável sorovar infectante ${ }^{3}$. Dessa forma, observaram-se, nos cães, os sorovares: castellonis 39 (26,68\%); autumnalis - $26(19,12 \%)$; pyrogenes - 24 (17,65\%); icterobaemorrhagiae $15(11,03 \%)$; canicola - $13(9,56 \%)$; australis 6 (4,41\%); shermani - 5 (3,68\%); copenhageni$2(1,47 \%)$; grippotyphosa - 2 (1,47\%); brasiliensis, butembo, panama e wolffi - $1(0,73 \%)$ cada. O sorovar castellonis foi o mais encontrado no presente estudo, mostrando, assim, sua destacada freqüência nos cães do município e gerando subsídios para futuras pesquisas. É um sorovar que tem como reservatórios os roedores silvestres ${ }^{29}$.

A porcentagem verificada de $26,68 \%$ de anticorpos para o sorovar castellonis nos soros caninos de Botucatu, SP, corrobora os resultados obtidos por pesquisadores na Cidade do México, México, no qual também o sorovar castellonis foi o mais freqüente, em $50 \%$ dos cães sororreagentes ${ }^{26}$, demonstrando 
Tabela 3 - Análise, por conglomerados, da freqüência de resultados sorológicos de anticorpos contra Leptospira spp., em cães do município de Botucatu, por meio de estatística de varredura espacial, São Paulo, Brasil, 2001

\begin{tabular}{|c|c|c|c|c|c|c|}
\hline \multirow[t]{2}{*}{ Co-variável } & \multirow[t]{2}{*}{ Postos de vacinação } & \multicolumn{2}{|c|}{$\begin{array}{l}\text { Número de cães } \\
\text { reagentes à Leptospirose }\end{array}$} & \multirow[t]{2}{*}{$\mathrm{RR}$} & \multirow[t]{2}{*}{ RMV } & \multirow[t]{2}{*}{ P-value } \\
\hline & & Esperados & Observados & & & \\
\hline (sem co-variável) & $\begin{array}{l}\text { Jardim Continental, Vila } \\
\text { Antártica, Vila São Luís }\end{array}$ & 28,10 & 47 & 1,67 & 6,51 & 0,02 \\
\hline Idade ${ }^{a}$ & Vila São Luís & 8,43 & 19 & 2,25 & 5,21 & 0,03 \\
\hline $\operatorname{Sexo}^{\mathrm{b}}$ & $\begin{array}{l}\text { Jardim Continental, Vila } \\
\text { Antártica, Vila São Luís }\end{array}$ & 28,17 & 47 & 1,67 & 6,45 & 0,02 \\
\hline $\operatorname{Raça~}^{\mathrm{c}}$ & $\begin{array}{l}\text { Jardim Continental, Vila } \\
\text { Antártica, Vila São Luís }\end{array}$ & 28,04 & 47 & 1,68 & 6,56 & 0,01 \\
\hline Acesso à rua ${ }^{d}$ & $\begin{array}{l}\text { Jardim Continental, Vila } \\
\text { Antártica, Vila São Luís }\end{array}$ & 28,92 & 47 & 1,63 & 5,88 & 0,02 \\
\hline Idade, sexo & Vila São Luís & 8,33 & 19 & 2,28 & 5,33 & 0,04 \\
\hline Idade, raça & Vila São Luís & 8,36 & 19 & 2,27 & 5,30 & 0,04 \\
\hline $\begin{array}{l}\text { Idade, acesso à } \\
\text { rua }\end{array}$ & Vila São Luís & 8,93 & 19 & 2,13 & 4,58 & 0,08 \\
\hline Idade, sexo, raça & Vila São Luís & 8,30 & 19 & 2,29 & 5,37 & 0,04 \\
\hline $\begin{array}{l}\text { Idade, sexo, raça, } \\
\text { acesso à rua }\end{array}$ & Vila São Luís & 9,18 & 19 & 2,07 & 4,29 & 0,11 \\
\hline
\end{tabular}

a 3m-1a; 1,1a-5a; a partir de 5,1a; ${ }^{\mathrm{b}}$ macho ou fêmea; ${ }^{\mathrm{c}}$ com ou sem raça definida; ${ }^{\mathrm{a}}$ com ou sem acesso à rua. RR: Risco Relativo; RMV: Razão deMáxima Verossimilhança

dessa forma, perempto-riamente, os possíveis e variados surgimentos de sorovares não tão comuns nos exames sorológicos rotineiros para leptospirose nos animais.

Foram observados casos de coaglutinações com títulos máximos e iguais para dois ou mais sorovares (Tabela 2), como, por exemplo, as pesquisas realizadas em soros caninos de Buenos Aires, Argentina ${ }^{30}$; Santana de Parnaíba, SP, Brasil ${ }^{28}$, e em Cali, Colômbia ${ }^{31}$. Esses autores ainda alertam como sendo um forte indicativo de reações cruzadas.

No presente trabalho, constatou-se que os soros dos cães machos apresentaram uma porcentagem levemente mais elevada que os das fêmeas, $54,9 \%$ e $45,1 \%$, respectivamente, frente à Leptospira spp. No entanto, em outras pesquisas foram encontradas prevalências muito superiores para machos 71,43\% em Buenos Aires, Argentina ${ }^{30}$, e nos soros dos cães machos $78,26 \%$ atendidos no Hospital Veterinário da Universidade da Paraíba no município de Patos, $\mathrm{PB}^{22}$. Porém, há discordância com outros relatos, como no resultado sorológico de cães errantes machos (19,23\%) e fêmeas $\left(80,77 \%\right.$ ) da cidade de Patos, PB $^{32}$, e de amostras sorológicass caninas machos (35,3\%) e fêmeas (64,7\%) em Ankara, Turquia $^{33}$. Pelo exposto, fica demonstrado a possibilidade de exposição dos animais à Leptospira spp., independente do sexo, pois os cães tem o hábito de cheirar a genitália dos outros ${ }^{8}$.

De acordo com a raça dos cães de Botucatu, SP, os sororreagentes sem raça definida tiveram uma taxa de $67,1 \%$ e os com raça definida $32,9 \%$, confirmando os achados de outra pesquisa realizada nesse Município em $1999^{34}$, na qual os animais sem raça definida representaram 84\%. Também em outro estudo em Santana de Parnaíba, $\mathrm{SP}^{28}$, os cães sorroreagentes sem raça definida corresponderam a $72,9 \%$ das amostras, evidenciando-se assim, que todos esses animais têm mais oportunidade de acesso à Leptospira spp.

Do ponto de vista espacial, os resultados da estatística de varredura apontaram apenas um conglomerado significativo, compreendido pela Vila São Luís, com percentual de cães sororreagentes acima do 


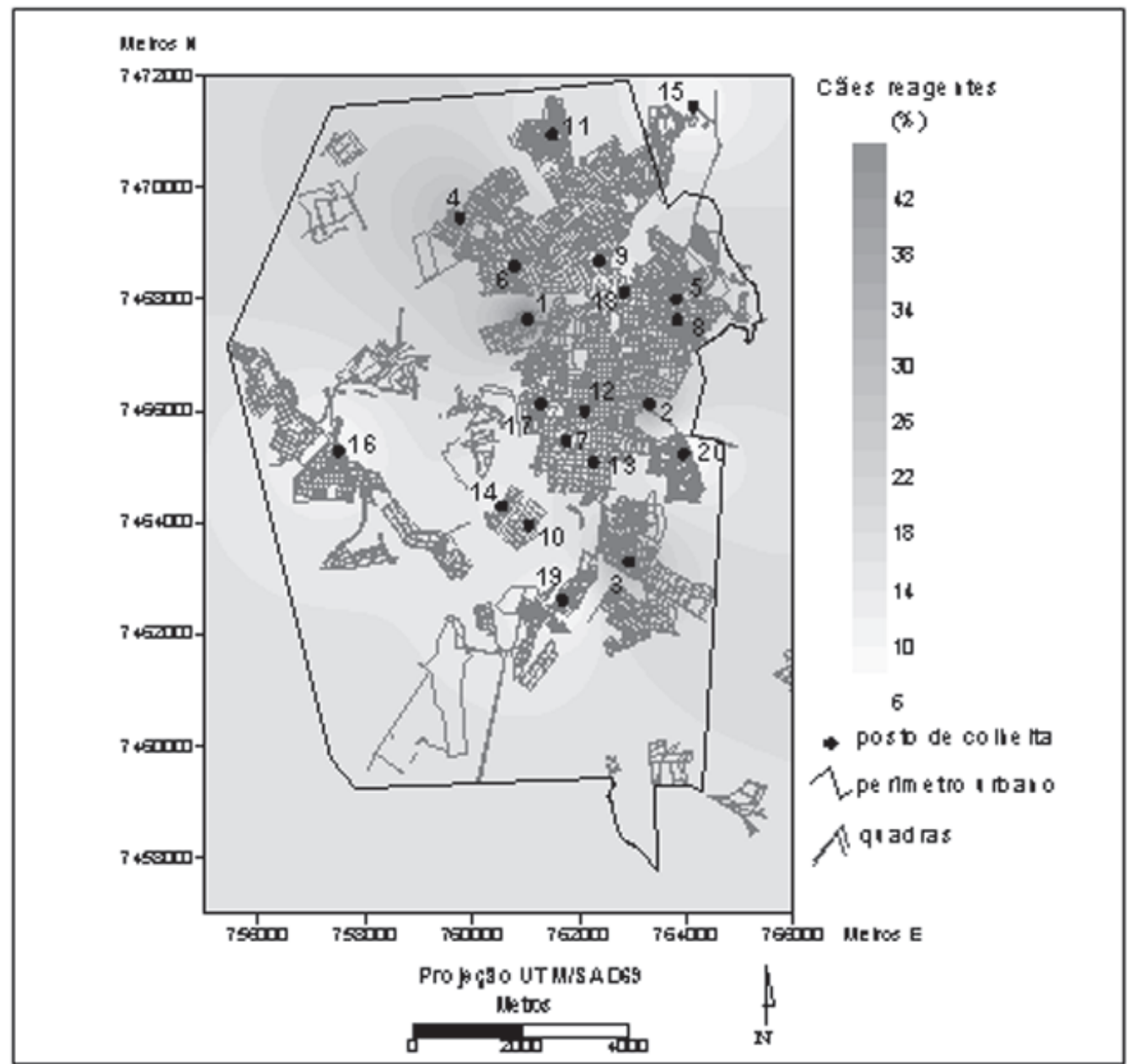

Figura 1 - Mapa da área territorial urbana de Botucatu, com a distribuição espacial dos resultados sorológicos obtida por meio de interpolação, São Paulo, Brasil, 2001

esperado apenas por acaso. Embora a proximidade espacial entre os bairros Vila São Luís, Vila Antártica e Jardim Continental permitisse agrupá-los num único conglomerado, numa análise geral, ao se incorporarem as co-variáveis, percebe-se que a situação da Vila São Luís é diferenciada. Apesar de próximos, os três bairros são periféricos e não apresentam conexão entre si, devido à topografia local e à presença de rios, indicando que o elevado percentual de cães reagentes se deve a condições distintas.

A análise dos fatores de risco mostrou que as co-variáveis idade e manejo de criação, possivelmente, explicam o excesso de cães sororreagentes na Vila São Luís.
Diferentemente do resultado geral, em que a taxa foi mais alta para cães com idade acima de 5 anos - 26,61\% (66/248) -, na Vila São Luís, o maior número de reagentes apresentou idade entre 1,1 e 5 anos (10/19). Nessa vila, a taxa de cães sororreagentes com acesso à rua - 52,63\% (10/19) - foi muito acima do resultado geral $-22,14 \%(93 / 420)$ -, mostrando que os cães da Vila São Luís estiveram expostos com mais freqüência e mais precocemente ao contato com as leptospiras.

Os resultados da estatística convencional já haviam apontado para a importância do manejo da criação, embora não pudessem indicar quando os resultados de um posto se 
tornavam preocupantes. A análise por conglomerados corroborou os achados da estatística convencional, esclarecendo se um número elevado ocorreu por acaso ou devido a um fator de risco de dimensão geográfica. Comparado com outros métodos estatísticos para avaliação de conglomerados, em epidemiologia, o teste de varredura espacial apresenta características particularmente apropriadas, pois permite considerar a densidade populacional heterogênea e as variáveis de risco conhecidas (tais como idade, sexo e raça), além de evitar o problema por pré-seleção ${ }^{35}$.

As técnicas de geoprocessamento e a análise estatística espacial ajudaram a compreender melhor a distribuição dos resultados sorológicos, na área territorial urbana do Município, e identificar os fatores de risco mais importantes. A identificação do conglomerado permite que sejam tomadas medidas preventivas localizadas.

\title{
Risk factor evaluation and spatial distribution analysis for urban dogs serum reactive to Leptospira spp
}

\begin{abstract}
We aimed to evaluate the risk factor of serum reactive dogs to antileptospire agglutinin and their spatial distribution in an urban area. We collected 1,000 blood samples from dogs at 20 immunization centers, homogeneously distributed in the urban area $\left(32 \mathrm{~km}^{2}\right)$ of Botucatu, Sao Paulo, Brazil. Diagnosis was made by microscopic serum agglutination using 24 serovars of Leptospira spp. Statistical analysis was performed by Goodman's test with 5\% of significance. Spatial clusters were tested by spatial scan statistic using SaTScan. We found that $17.9 \%$ dogs reacted to Leptospira spp. $(\mathrm{p}<0.0001)$. Dogs with street access $(22.14 \%)$ were more reactive $(p<0.05)$ than those without $(14.83 \%)$. The scan test indicated only one significant cluster influenced by age. Incorporating each one of the co-variables gender, breed, and street access to age, we found that street access was the most important. Street access and age were the most important risk factors in the large number of reactive animals in the cluster, with the castellonis serovar being the most reactive in urban dogs. The identification of a cluster with more reactive dogs than expected allows local preventive measures to be taken.
\end{abstract}

Key-words : Leptospirose. Dogs. Risk factors.

\section{Referências}

1 GReENE, C. E.; MILLER, M. A.; BROW, C. A. Leptospirose. In: GREENE, C .E. Infectious diseases of the dog and cat. 2th ed. Philadelphia: W.B. Saunders, 1998. p.273-281.

2 SANTORO, M. L. et al. Decreased erythrocyte osmotic fragility during canine leptospirosis. Rev. Inst. Med. Trop. São Paulo, v. 36, n. 1, p. 1-5, 1994.

3 BOLIN, C. A. Diagnosis of leptospirosis: A reermerging disease of companion animals. Semin. Vet. Med. Surg. (Small Animal), v. 11, n. 3, p. 166-171, 1996.

4 LEVETT, P. N. Leptospirosis: re-emerging or rediscovered disease?. J. Med. Microbiol., v. 48, n. 2, p. 417-418, 1999.

5 WEEKES, C.C.; EVERARD, C.O.R.; LEVETT, P.N.
Seroepidemiology of canine leptospirosis on the island of Barbados. Vet. Microbiol., v. 51, p. 215-222, 1997.

6 CÔRTES, J. A. Epidemiologia: conceitos e princípios fundamentais. São Paulo: Varela, 1993. 227 p.

7 GENOVEZ, M. E. Leptospirose em cães. Pet. Vet., v. 1, n. 1, p. 6-9, 1996.

8 CORRÊA, W. M.; CORRÊA, C. N. M. Leptospira canina. In: Enfermidades infecciosas dos mamíferos domésticos. 2. ed. Rio de Janeiro: MEDSI, 1992. p. 233-240.

9 PRESCOTT, J. F.; KEY, D.; OSUCH, M. Ontario: leptospirosis in dogs. Can. Vet. J., v. 40, p. 430 - 431, 1999.

10 LEVETT, P. N. Leptospirosis. Clin. Microbiol. Rev., v. 14, n. 2, p. 296-326, 2001.

11 BABUDIERE, B. Animal reservoirs of leptospires. 
Ann. N. Y. Acad. Sci., v. 70, p. 393-413, 1958.

12 PRESCOTT, J. F. et al. Is canine leptospirosis underdiagnosed in southern Ontario? A case report and serological survey. Can. Vet. J., v. 32, p. 481-486, 1991.

13 BRASIL. Ministério da Saúde. Fundação Nacional de Saúde. Centro Nacional de Epidemiologia. Coordenação de Controle de Zoonoses e Animais Peçonhentos. Manual de Leptospirose. 2. ed. Brasília: Fundação Nacional de Saúde, 1995. 98 p.

14 KNOX, E.G. Evaluation of a proposed breast cancer screening regimen. Br. Med. J., v. 297, p. 650-654, 1988.

15 INSTITUTO BRASILEIRO DE GEOGRAFIA E ESTATÍSTICA. IBGE, Base de Informações Municipais, Malha Municipal Digital 2000. Disponível em: <http:/ /www.ibge.gov.br/cidadesat/default.php > . Acesso em: 20 jun. 2004.

16 COCHRAN, W. Sampling techniques. 3th ed. New York: John Wiley; 1977.

17 GOODMAN, L.A. Simultaneous confidence intervals for contrasts among multinomial populations. Ann. Math. Stat., v. 35, n. 2, p. 716-725, 1964.

18 GOODMAN, L. A. On simultaneous confidence intervals for multinomial proportions. Technometrics, v. 7, n. 2 , p. 247-254, 1965.

19 STREINER, D. L.; NORMAN, G. R. Biostatistics: the base essentials. St. Louis: Mosby - Year Book, 1994. 260 p.

20 KULLDORFF, M. et al. Evaluating cluster alarms: a space-time scan statistic and brain cancer in Los Alamos, New Mexico. Am. J. Pub. Health, v. 88, p. 1377 1380, 1998.

21 FAVERO, A. C. M. et al. Sorovares de leptospiras predominantes em exames sorológicos de bubalinos, ovinos, caprinos, eqüinos, suínos e cães de diversos estados brasileiros. Ci. Rural, v. 32, n. 4, p. 613-619, 2002.

22 ALVES, C. J. et al. Avaliação dos níveis de aglutininas anti-leptospira em cães no município de Patos - PB, Brasil. Rev. Bras. Ci. Vet., v. 7, n. 1, p. 17-21, 2000.

23 THIRUNAVUKKARASU, P. S. et al. Ocular manifestations in canine leptospirosis. Indian. Vet. J., v. 72, p. 200-201, 1995.

24 MYBURGH, J. G.; POSNETT, S. J.; LAWRENCE, J. $V$. Serological survey for canine leptospirosis in the Pretoria area. J. S. Afr. Vet. Assoc., v. 64, n.1, p. 37-38, 1993.

25 VIEGAS, S. A. R. A.; CALDAS, E. M.; OLIVEIRA, E. M. D. Aglutininas anti-leptospira em hemosoro de animais domésticos de diferentes espécies, no Estado da Bahia, 1997/1999. Rev. Bras. Saúde Prod. Anim., v. 1, p. 1-6, 2001.
26 FLORES, A. R. et al. Seroprevalencia de leptospiroses en perros callejeros del norte de la ciudad de México. Vet. Méx., v. 30, n. 1, p. 105-107, 1999.

27 FURTADO, L. R. I. et al. Prevalência e avaliação de fatores de risco à leptospirose canina, no município de Pelotas, RS. Arq. Inst. Biol., v. 64, n. 1, p. 57-61, 1997.

28 MASCOLLI, R. et al. Inquérito sorológico para leptospirose em cães do município de Santana de Parnaíba, São Paulo, utilizando a campanha de vacinação anti-rábica do ano de 1999. Arq. Inst. Biol., v. 69, n. 2, p. 25-32, 2002.

29 BARANTON, G. DNA relatedness of serovars. [Online] Prepublication list. Unité de Bactériologie Moléculaire et Médicale. Institut Pasteur. Leptospira Molecular Biology. Paris: Institut Pasteur, 1998. Disponível em: < http://www.pasteur.fr/recherche/ leptospira. html >. Acesso em: 20 mar. 2002.

30 RUBEL, D. et al. Leptospira interrogans en una población canina del Gran Buenos Aires: variables asociadas con la seropositividad. Rev. Panam. Salud. Publica, v. 2, n. 2, p. 102-105, 1997.

31 RODRIGUEZ, A. L. et al. Evidencia de exposición a Leptospira en perros callejeros de Cali. Biomédica, $\mathrm{v}$. 24, p. 291-295, 2004.

32 BATISTA, C. S. A. et al. Soroprevalência de leptospirose em cães errantes da cidade de Patos, Estado da Paraíba, Brasil. Braz. J. Vet. Res. Anim. Sci., v. 41, p. 131-136, 2004.

33 ASLANTAa, Ö. et al. Seroepidemiology of leptospirosis, toxoplasmosis, and leishmaniosis among dogs in Ankara, Turkey. Vet. Parasitol., v. 129, p. 187191, 2005.

34 MODOLO, J. R. et al. Inquérito soroepidemiológico para leptospirose canina, no município de Botucatu SP. In: CONGRESSO BRASILEIRO DE VETERINÁRIA, 27., Águas de Lindóia, 2000. Anais: Águas de Lindóia, 2000. p. 95.

35 KULLDORFF, M. et al. Breast cancer clusters in the Northeast United States: a geographic analysis. Am. J. Epidemiol., v. 146, p. 161-170, 1997. 